\title{
Do Bioactive Carotenoids Contribute to the Color of Edible Mushrooms?
}

\author{
Bárbara Ribeiro ${ }^{1}$, Paula Guedes de Pinho ${ }^{*}, 2$, Paula B. Andrade ${ }^{1}$, Carla Oliveira ${ }^{3}$, \\ António César Silva Ferreira ${ }^{3}$, Paula Baptista ${ }^{4}$, Patrícia Valentão ${ }^{*}, 1$
}

\author{
${ }^{I}$ REQUIMTE/Laboratório de Farmacognosia, Departamento de Química, Faculdade de Farmácia, Universidade do \\ Porto, R. Aníbal Cunha 164, 4050-047 Porto, Portugal \\ ${ }^{2}$ REQUIMTE/Laboratório de Toxicologia, Departamento de Ciências Biológicas, Faculdade de Farmácia, \\ Universidade do Porto, R. Anibal Cunha 164, 4050-047 Porto, Portugal \\ ${ }^{3}$ Interface A4, Escola Superior de Biotecnologia, Universidade Católica Portuguesa, Rua António Bernardino de \\ Almeida, 4200-072 Porto, Portugal \\ ${ }^{4}$ CIMO/School of Agriculture, Polytechnic Institute of Bragança, Campus Sta Apolónia, Apt. 1171, 5301-854 Bragança \\ Portugal
}

\begin{abstract}
Carotenoids are biologically active phytochemicals present as micro-components in fruits and vegetables, being responsible for their yellow, orange and red colors. The chromatographic behavior and the UV absorption spectrum provided by HPLC-DAD analysis constitute the clues for their identification. Mushrooms are of increasing importance in modern nutrition and medicine, due to the presence of metabolites with pharmacological potential. In this work, samples of wild and commercial mushroom species (Agaricus bisporus, Amanita caesarea, Amanita rubescens, Boletus edulis, Cantharellus cibarius, Fistulina hepatica, Hydnum rufescens, Hygrophorus agathosmus, Pholiota nameko, Pleurotus ostreatus, Russula cyanoxantha, Suillus bellini, Suillus bovinus, Suillus granulatus, Suillus luteus, Tricholoma equestre and Tricholoma portentosum) were screened by HPLC-DAD for the presence of carotenoids. By applying this methodology to 22 samples, comprising either lyophilized or fresh materials, only $\beta$-carotene was found and just in $C$. cibarius species. The occurrence of this pigment in other three of the analyzed species previously described raises some questions about the methodology used.
\end{abstract}

Keywords: Carotenoids, Edible mushrooms, HPLC-DAD.

\section{INTRODUCTION}

Mushrooms are macrofungi with a distinctive fruiting body that are consumed as a delicacy, particularly for their specific aroma and texture. They constitute an integral part of the normal human diet, presenting an increasing share, and both fresh and preserved fruiting bodies of plenty of species can be culinary-processed in different manners [1]. Mushrooms have also been reported as source of pharmacologically active compounds, to which activities like antimicrobial, antitumor, cytostatic, hypoglycemic, antiinflammatory or antioxidant are attributed [2].

Carotenoids biosynthesis occurs in bacteria, fungi, algae, and plants. Animals are unable to synthesize them, so they obtain these molecules via ingestion [3]. In addition to very few bacterial carotenoids with 30,45 or 50 carbon atoms, $\mathrm{C}_{40}$-carotenoids constitute the majority of the known structures [4]. More than 600 carotenoids have been

*Address correspondence to these authors at the Laboratório de Farmacognosia, Faculdade de Farmácia, Universidade do Porto, R. Aníbal Cunha 164, 4050-047 Porto, Portugal; Tel: +351 222078934; Fax: +351 222003977; E-mail:valentao@ff.up.pt and

REQUIMTE/Laboratório de Toxicologia, Departamento de Ciências Biológicas, Faculdade de Farmácia, Universidade do Porto, R. Aníbal Cunha 164, 4050-047 Porto, Portugal; E-mail: pguedes@ff.up.pt identified in nature so far. Nevertheless, only about 40 are present in a typical human diet and about 20 of them have been identified in human blood and tissues. Close to $90 \%$ of the carotenoids in the diet and human body is represented by $\beta$-carotene, $\alpha$-carotene, lycopene, lutein and cryptoxanthin [5].

Characteristic fungal carotenoids possess 4-keto groups, may be monocyclic, or exhibit 13 conjugated double bonds [4]. The conjugated double bounds are responsible for the typical colors of these molecules (yellow, orange, red and purple) because they absorb between 440 and $490 \mathrm{~nm}$ of the light spectrum [5]. In fungi, these molecules arise from the mevalonate biosynthetic pathway. Mevalonate is formed from acetyl-CoA via hydroxymethylglutaryl-CoA. The subsequent steps involve two kinase reactions yielding mevalonic acid pyrophosphate, which is then decarboxylated to isopentenyl pyrophosphate, the building unit for the synthesis of terpenoids [4].

The role of carotenoids in organisms is to protect cells against the lethal combination of light (photoprotectors) and oxygen (antioxidants). The high number of conjugated double bonds makes carotenoids more reactive and able to function as antioxidants, namely against oxygen radicals. The carotenoids associated to membranes can substantially stabilize them and modify their thickness, strength and 
fluidity, subsequently affecting many of their functions. These metabolites can also act as photoreceptors $[5,6]$.

Information on carotenoids in mushrooms is scarce. Nevertheless, previous studies described the presence of $\beta$ carotene in Cantharellus cibarius [7-11], Agaricus bisporus [11,12], Pleurotus ostreatus [11,13], Boletus edulis [9,11], Suillus bovinus [11] and Tricholoma equestre [11], of lycopene in C. cibarius [7-9,11], A. bisporus [11,12], B. edulis [9,11], P. ostreatus [11], S. bovinus [11] and $T$. equestre [11], of lutein, $\alpha$-carotene [7] and canthaxanthin [14] in C. cibarius and of $\gamma$-carotene, auroxanthin and neurosporene in B. edulis [15].

The climatic characteristics and flora diversity of Northeastern Portugal renders this to be one of the European regions with higher wild edible mushrooms variety, some of them with great gastronomic and economic impact. The mushroom species growing there are usually consumed fresh, dried, during the off-season, or canned. Despite their consumption and increasing exportation to foreign countries, the available data regarding the nutritive valorization of the species are still very scanty. A previous study [16] revealed the presence of volatile norisoprenoids (apocarotenals), such as $\beta$-ionone, trans-geranyl acetone and $(E, E)$-farnesyl acetone, in some wild mushroom species collected in this region. Those are odor active substances that can be formed from carotenoids degradation. $\beta$-Ionone can arise from the degradation of $\beta$-carotene, which contains two nonsubstituted $\beta$-ionone rings in their ends [17]. Acyclic tetraterpenoids, such as lycopene, can give rise to geranyl acetone and farnesyl acetone by oxidative degradation [17].

In the sequence of the chemical characterization that we have been developing on mushrooms collected in Trás-osMontes region, namely focusing primary and secondary metabolites [16,18-23], a study was undertaken on the carotenoids of species commonly consumed in Portugal. For this purpose, samples of wild mushroom species (Suillus bellini, Suillus luteus, Suillus granulatus, S. bovinus, Hygrophorus agathosmus, Amanita rubescens, Russula cyanoxantha, B. edulis, T. equestre, Fistulina hepatica, Amanita caesarea, Hydnum rufescens and C. cibarius) and five commercially available ones (C. cibarius, Pholiota nameko, A. bisporus, $P$. ostreatus and Tricholoma portentosum) were analyzed by HPLC-DAD.

\section{MATERIALS AND METHODS}

\subsection{Standards and Reagents}

$\beta$-Carotene and lutein were supplied by Sigma (St. Louis, MO, USA). Ethyl acetate, acetonitrile, diethyl ether, acetone and hexane were obtained from Merck (Darmstadt, Germany). $\beta$-Apo-8'-carotenal was obtained from Fluka (Buchs, Switzerland). Neoxanthin and violaxanthin were purchased to CaroteNature GmbH (Lupsingen, Switzerland). The water was treated in a Milli-Q water purification system (Millipore, Bedford, MA).

\subsection{Samples}

The characterization of the analyzed samples is presented in Table 1. Seventeen samples (samples 1-17) of wild mushroom fruiting bodies were collected from different places in Trás-os-Montes (North-eastern Portugal).
Taxonomic identification followed that of several authors [24-29]. Representative voucher specimens were deposited at the herbarium of School of Agriculture from Polytechnic Institute of Bragança. Five samples (samples 18-22) were acquired in a local market. Samples 1, 2, 4, 6, 8-15 and 17 were freeze-dried in a Labconco 4.5 Freezone apparatus (Kansas City, MO) and stored in a desiccator until analysis. Fresh mushroom samples were kept refrigerated until analysis, which was performed within 4 days.

\subsection{Extracts Preparation}

For carotenoids characterization, ca. $50 \mathrm{~g}$ of fresh mushrooms or ca. $10 \mathrm{~g}$ of powdered lyophilized samples were used. The fresh ones were homogenized using a Turrax homogenizer at $9500 \mathrm{rpm}$, for $15 \mathrm{~min}$. In both cases, the samples were picked with $200 \mu \mathrm{L}$ of internal standard (170 $\mathrm{mg} / \mathrm{L}$ of $\beta$-apo- 8 '-carotenal). Due to the hydrophobic character of carotenoids, extraction was carried out with ether/hexane $(1: 1, \mathrm{v} / \mathrm{v})$. The extraction was repeated five times with $100 \mathrm{~mL}$ of solvent, under stirring at $450 \mathrm{rpm}$ for $10 \mathrm{~min}$, at room temperature. The final combined extract was concentrated to dryness under reduced pressure and redissolved in $1 \mathrm{~mL}$ of acetone/hexane $(1: 1, \mathrm{v} / \mathrm{v})$ for HPLCDAD determination. Light exposure was minimized during samples' preparation to avoid photoisomerization [30].

\subsection{Carotenoids Analysis by HPLC-DAD}

A Beckman model 126 quaternary solvent system, equipped with System 32 Karat software and a 168 rapidscanning UV-visible photodiode array detector, was used. The absorption spectra were recorded between 270 and 600 $\mathrm{nm}$. The injection volume was $20 \mu \mathrm{L}$. The analysis was performed using a Nova-Pack C18, $60 \AA, 4 \mu \mathrm{m}$ particles (3.9 $\times 300 \mathrm{~mm}$ ) column (Waters). Elution was developed with ethyl acetate (solvent A) and acetonitrile/water $(9: 1, \mathrm{v} / \mathrm{v}$, solvent B) at a flow rate of $1 \mathrm{~mL} / \mathrm{min}$. The following gradient was employed: $0-31 \mathrm{~min}(0-60 \% \mathrm{~A}) ; 31-46 \mathrm{~min}$ $(60 \% \mathrm{~A})$; $46-51 \min (60-100 \% \mathrm{~A})$; $51-55 \min (100 \% \mathrm{~A})$; $55-$ $60 \min (100-0 \%$ A); $60-65 \min (0 \%$ A) [30].

Carotenoids were identified by comparison of their absorption spectra and retention times with those of commercial standards. The content of $\beta$-carotene was calculated on the basis of a calibration curve constructed using authentic standard $(y=0.017 x+0.7596)$.

\section{RESULTS AND DISCUSSION}

The chromatographic behavior and the UV absorption spectrum provided by HPLC-DAD analysis constitute the clues for the identification of carotenoids, being related with their structures. Both the wavelengths of maximum absorption and the shape of the spectrum are characteristic of the chromophore.

First we analyzed the lyophilized material of wild $S$. bellini, S. luteus, S. granulatus, S. bovinus, H. agathosmus, $A$. rubescens, $R$. cyanoxantha, $B$. edulis, $T$. equestre, $F$. hepatica, A. caesarea, $H$. rufescens and $C$. cibarius fruiting bodies (samples 1, 2, 4, 6, 8-15 and 17) (Table 1). However, only $\beta$-carotene was detected, in vestigial amounts and just in C. cibarius sample (sample 17), although it was also described in B. edulis [9,11], S. bovinus [11] and T. equestre [11]. In addition, despite other carotenoids are reported to 
Table 1. Characterization of the Mushroom Samples

\begin{tabular}{|c|c|c|c|c|}
\hline 1 & Suillus bellini & Lyophilized & Bragança & Pinus pinaster \\
\hline 3 & S. luteus & Fresh & Vinhais & Pinus pinaster + Castanea sativa \\
\hline 4 & Suillus granulatus & Lyophilized & Bragança & Pinus pinaster \\
\hline 6 & Suillus bovinus & Lyophilized & Grandais & Pinus pinaster + Castanea sativa \\
\hline 7 & S. bovinus & Fresh & Grandais & Pinus pinaster + Castanea sativa \\
\hline 8 & Hygrophorus agathosmus & Lyophilized & Bragança & Pinus pinaster \\
\hline 9 & Amanita rubescens & Lyophilized & Bragança & Quercus pyrenaica \\
\hline 13 & Fistulina hepatica & Lyophilized & Bragança & Castanea sativa \\
\hline 14 & Amanita caesarea & Lyophilized & Grandais & Castanea sativa \\
\hline 15 & Hydnum rufescens & Lyophilized & Grandais & Castanea sativa \\
\hline 16 & H. rufescens & Fresh & Grandais & Castanea sativa \\
\hline 17 & Cantharellus cibarius & Lyophilized & Bragança & Castanea sativa \\
\hline 18 & C. cibarius & Fresh & Commerce & \\
\hline 19 & Pholiota nameko & Fresh & Commerce & \\
\hline 20 & Agaricus bisporus & Fresh & Commerce & \\
\hline
\end{tabular}

occur in C. cibarius [7-9,14], B. edulis [9,15], S. bovinus [11] and $T$. equestre [11], no other compound was noticed in the lyophilized samples.

Lyophilization is widely considered the appropriate processing technique to preserve biological samples that have to be stored before carotenoid analysis. However, carotenoids are degraded during lyophilization. Additionally, this procedure increases sample porosity, thus raising exposure of carotenoids to oxygen during storage [31]. As so, in order to check whether the absence of carotenoids in the samples was a consequence of the lyophilization procedure we searched for the presence of these compounds in the available fresh samples of $S$. luteus, $S$. granulatus, $S$. bovinus, $H$. rufescens and $C$. cibarius (samples 3, 5, 7, 16 and 18) (Table 1). Fresh material of other species, namely $P$. nameko, A. bisporus, $P$. ostreatus and $T$. portentosum, was also analyzed (samples 19-22) (Table 1).

The analysis of the extracts obtained from the several fresh mushrooms allowed the identification of $\beta$-carotene only in C. cibarius (sample 18) (Fig. 1). This pigment had already been reported in this mushroom [7-11], as well as in other species of the same genus, namely in Cantharellus lateritius, Cantharellus tabernensis [10] and Cantharellus cinnabarinus [32]. The amount of this compound in the fresh sample 18 was clearly higher than that in the lyophilized one (sample 17), corresponding to $51.2 \mu \mathrm{g} / 100 \mathrm{~g}$. The different amounts may be related to the negative effect of the lyophilization procedure on carotenoids, but the variability between individuals cannot be excluded.

With respect to the remaining fresh samples (samples 3, $5,7,16,19-22)$, although several peaks were detected no carotenoid-like spectrum was noticed.

It should be highlighted that the color of some mushroom species, such as $C$. cibarius, $P$. nameko and $S$. bovinus, was a contributing factor to carry out the present study. Like $C$. cibarius, the other two mushroom species present a slight orange color, thus suggesting the possible occurrence of $\beta$ carotene. However, this carotenoid was not identified in any of them.

Regarding $H$. rufescens, $S$. granulatus and S. luteus, as neither lyophilized nor fresh samples presented carotenoids, and considering that data for these matrices is not found in literature, it can be speculated the absence of these kind of compounds to be a characteristic of the species.

In what concerns to $S$. bellini, $H$. agathosmus, $A$. rubescens, $R$. cyanoxantha, $F$. hepatica and $A$. caesarea, only lyophilized material was analyzed. As no carotenoid was found, not only the negative impact of this drying procedure on these compounds [31], but also the possibility that their absence corresponds to a property of the species, have to be taken into consideration. 


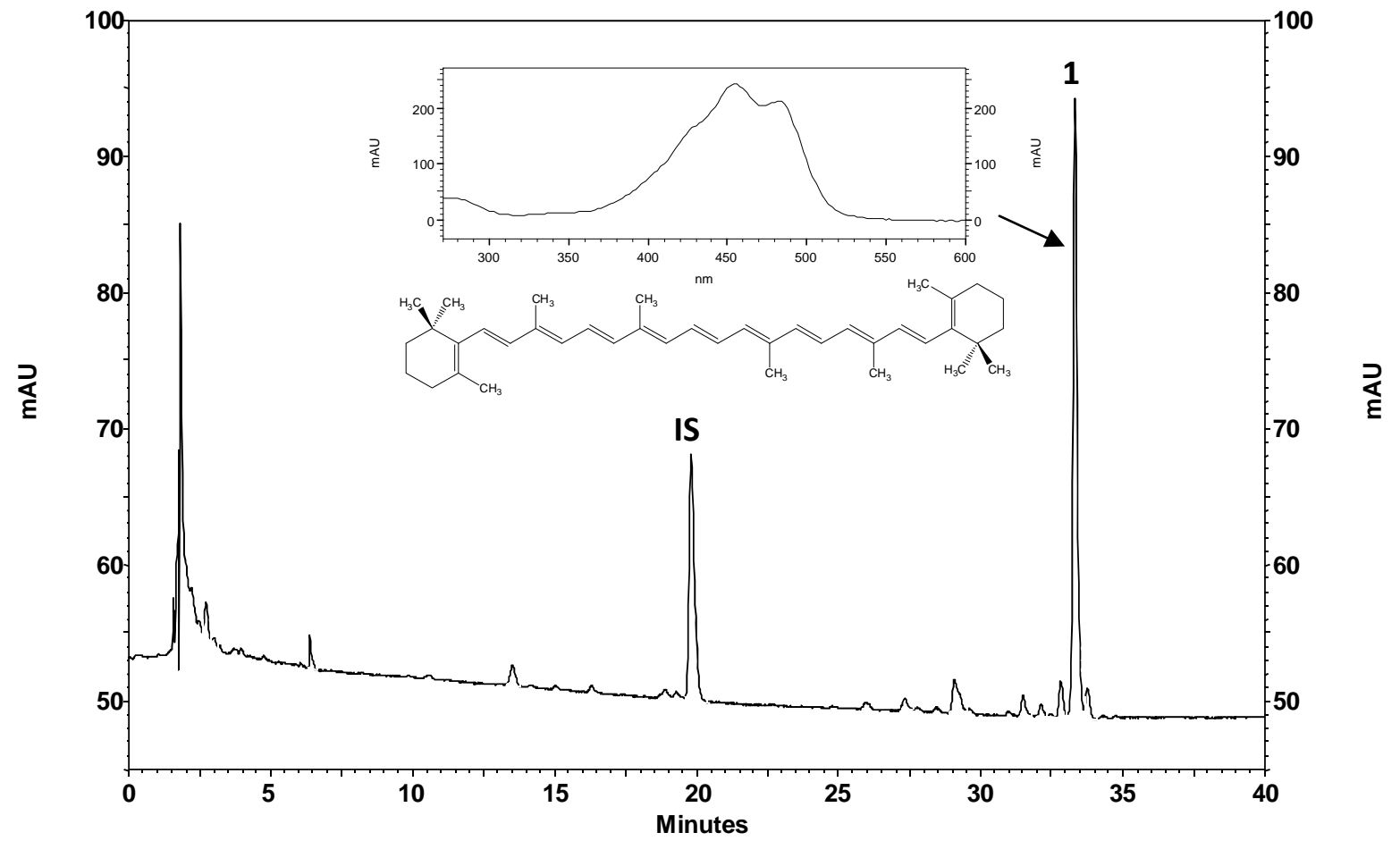

Fig. (1). HPLC-DAD Chromatogram of Carotenoids in Fresh Cantharellus cibarius. Detection at $447 \mathrm{~nm}$. (1) $\beta$-Carotene; (IS) Internal Standard.

As referred above, $\beta$-carotene and lycopene were previously described in B. edulis [9,11] and T. equestre [11]. However, their identification was achieved by measuring the absorbance of a solution at 453, 505, 645 and $663 \mathrm{~nm}$, a spectrophotometric method not as accurate as HPLC-DAD, which may suffer the interference of other compounds absorbing at the same wavelengths that could lead to the misidentification of carotenoids in the sample. The absence of $\gamma$-carotene, auroxanthin and neurosporene, also reported in this species [15], may be due to the use of a different extraction procedure. Nevertheless, the effect of the lyophilization process cannot be excluded.

As for the fresh samples, the absence of $\beta$-carotene in $T$. portentosum has already been reported [33], which was confirmed in the present study. Although $\beta$-carotene and lycopene were previously described in A. bisporus [12], $S$. bovinus [11] and P. ostreatus [11,13], they were not detected in our work. However, the three species were analyzed by the spectrophotometric method referred above for $B$. edulis and $T$. equestre. In addition, for $P$. ostreatus a different extraction procedure was also performed, followed by HPLC-UV with detection at $470 \mathrm{~nm}$ [13]. Both methodologies are not as precise as HPLC-DAD, lacking information on UV spectra. In addition, interferences may also occur, as already mentioned. In $P$. nameko no carotenoid was found, for which other pigments may be responsible for its orange color.

$\beta$-Carotene assumes a great biological importance. It is the precursor of vitamin $\mathrm{A}$, decreases cancer risk, has a potent antioxidant ability that contributes to protection against cardiovascular diseases, as it inhibits LDLcholesterol oxidation preventing atherosclerosis development, reduces the photosensitivity, stimulates the immune system response, namely to HIV, and scavenges peroxyl radicals, avoiding lipids oxidation and subsequent degradation [3438]. Therefore, according to the results obtained, $C$. cibarius may contribute for beneficial effects in human organism.

\section{CONCLUSIONS}

The screening of carotenoids in both lyophilized and fresh samples of edible mushrooms species by HPLC-DAD did not confirm their presence in some of them, for which this kind of compounds was previously reported. This indicates that not always the results obtained by using less precise methodologies for the detection of carotenoids are confirmed when more sophisticated techniques are applied, despite the existence of chemical variability within the species, as each individual results from the cross-breeding of different hyphas, presenting a distinct genotype. Within the twenty two analyzed samples, only $\beta$-carotene was found and just in $C$. cibarius material, being responsible, at least partially, for the orange color of this species.

\section{ACKNOWLEDGEMENTS}

The authors are grateful to Fundação para a Ciência e a Tecnologia (FCT) for grant no. PEst-C/EQB/LA0006/2011. Bárbara Ribeiro is indebted to $\mathrm{FCT}$ for the grant (SFRH/BD/22108/2005).

\section{CONFLICT OF INTEREST}

There is no conflict of interest.

\section{REFERENCES}


[1] Kalač, P. Chemical composition and nutritional value of European species of wild growing mushrooms: A review. Food Chem., 2009, $113,9-16$.

[2] Lindequist, U.; Niedermeyer, T.H.J.; Jülich, W.-D. The pharmacological potential of mushrooms. Evid. Based Complement. Alternat. Med., 2005, 2, 285-299.

[3] Rodríguez-Bustamante, E.; Sánchez, S. Microbial production of $\mathrm{C}_{13}$-norisoprenoids and other aroma compounds via carotenoid cleavage. Crit. Rev. Microbiol., 2007, 33, 211-230.

[4] Sandmann, S. Carotenoid biosynthesis and biotechnological application. Arch. Biochem. Biophys., 2001, 385, 4-12.

[5] Rao, A.V.; Rao, L.G. Carotenoids and human health. Pharmacol. Res., 2007, 55, 207-216.

[6] During, A.; Harrison, E.H. Intestinal absorption and metabolism of carotenoids: insights from cell culture. Arch. Biochem. Biophys., 2004, 430, 77-88.

[7] Heinonen, M.I.; Ollilainen, V.; Linkola, E.K.; Varo, P.T.; Koivistoinen, P.E. Carotenoids in Finnish foods: vegetables, fruits, and berries. J. Agric. Food Chem., 1989, 37, 655-659.

[8] Barros, L.; Venturini, B.A.; Baptista, P.; Estevinho, L.M.; Ferreira, I.C.F.R. Chemical composition and biological properties of Portuguese wild mushrooms: A comprehensive study. J. Agric. Food Chem., 2008, 56, 3856-3862.

[9] Barros, L.; Cruz, T.; Baptista, P.; Estevinho, L.M.; Ferreira, I.C.F.R. Wild and commercial mushrooms as source of nutrients and nutraceuticals. Food Chem. Toxicol., 2008, 46, 2742-2747.

[10] Mui, D.; Feibelman, T.; Bennett, J.W. A preliminary study of the carotenoids of some North American species of Cantharellus. Int. J. Plant Sci., 1998, 159, 244-248.

[11] Robaszkiewicz, A.; Bartosz, G.; Ławrynowicz, M.; Soszyński, M. The role of polyphenols, $\beta$-carotene, and lycopene in the antioxidative action of the extract of dried, edible mushrooms. $J$. Nutr. Metab., 2010, 2010, 173274.

[12] Barros, L.; Falcão, S.; Baptista, P.; Freire, C., Vilas-Boas, M.; Ferreira, I.C.F.R. Antioxidant activity of Agaricus sp. mushrooms by chemical, biochemical and electrochemical assays. Food Chem., 2008, 111, 61-66.

[13] Jayakumar, T.; Thomas, P.A.; Geraldine, P. In vitro antioxidant activities of an ethanolic extract of the oyster mushroom, Pleurotus ostreatus. Innovat. Food Sci. Emerg. Tech., 2009, 10, 228-234.

[14] Zürcher, M.; Niggli, U.A.; Steck, A.; Pfander, H.) Oxidation of carotenoids - I. Dihydrooxepin derivatives as products of oxidation of canthaxanthin and $\beta, \beta$-carotene. Tetrahedron. Lett., 1997, 38, 7853-7856.

[15] Czeczuga, B. Investigations on carotenoids in fungi IV. Members of the Boletus genus. Plant Foods Hum. Nutr., 1978, 28, 37-43.

[16] Guedes de Pinho, P.; Ribeiro, B.; Gonçalves, R.F.; Baptista, P.; Valentão, P., Seabra, R.M.; Andrade, P.B. Correlation between the pattern volatiles and the overall aroma of wild edible mushrooms. J. Agric. Food Chem., 2008, 56, 1704-1712.

[17] Waites, M.J.; Morgan, N.L.; Rockey, J.S.; Higton, G. Industrial microbiology: An Introduction, Wiley-Blackwell: New Jersey, 2001.

[18] Valentão, P.; Andrade, P.B.; Rangel, J.; Ribeiro, B.; Silva, B.M.; Baptista, P.; Seabra, R.M. Effect of the conservation procedure on the contents of phenolic compounds and organic acids in chanterelle (Cantharellus cibarius) mushroom. J. Agric. Food Chem., 2005, 53, 4925-4931.

[19] Ribeiro, B.; Valentão, P.; Baptista, P.; Seabra, R.M.; Andrade, P.B. Phenolic compounds, organic acids profiles and antioxidative properties of beefsteak fungus (Fistulina hepatica). Food Chem. Toxicol., 2007, 45, 1805-1813.

[20] Ribeiro, B.; Rangel, J.; Valentão, P.; Baptista, P.; Seabra, R.M.; Andrade, P.B. Contents of carboxylic acids and two phenolics and antioxidant activity of dried Portuguese wild edible mushrooms. $J$. Agric. Food Chem., 2006, 54, 8530-8537.

[21] Ribeiro, B.; Lopes, R.; Andrade, P.B.; Seabra, R.M.; Gonçalves, R.F.; Baptista, P.; Quelhas, I.; Valentão, P. Comparative study of phytochemicals and antioxidant potential of wild edible mushroom caps and stipes. Food Chem., 2008, 110, 47-56.

[22] Ribeiro, B.; Andrade, P.B.; Silva, B.M.; Baptista, P.; Seabra, R.M.; Valentão, P. Comparative study on free amino acid composition of wild edible mushroom species. J. Agric. Food Chem., 2008, 56, 10973-10979.

[23] Ribeiro, B.; Guedes de Pinho, P.; Andrade, P.B.; Baptista, P.; Valentão, P. Fatty acid composition of wild edible mushrooms species: A comparative study. Microchem. J., 2009, 93, 29-35.

[24] Bas, C.; Kuyper, T.W.; Noordeloos, M.E.; Vellinga, E.C. Flora Agaricina Neerlandica: Critical monographs on families of agarics and boleti occurring in the Netherlands, Vol. 1-5. A.A. Balkema: Rotterdam, 1990-2001, p. 464.

[25] Bom, M. Guia de campo de los hongos de Europa, Ediciones Omega: Barcelona, 1988.

[26] Courtecuisse, R. Mushrooms of Britain and Europe, HarperCollins Publishers: London, 1999.

[27] Courtecuisse, R.; Duhem, B. Mushrooms and toadstools of Britain and Europe, HarperCollins Publishers: London, 1995, p. 535.

[28] Marchand, A. Champignons du Nord et du Midi, Tome 1-9. Soc. Mycol. Pyrénées Mediterranéenes: Perpignan, 1971-1986.

[29] Moser, M. Keys to Agarics and Boleti (Poliporales, Boletales, Agaricales, Russulales), Roger Phillips: London, 1983, p. 535.

[30] Mendes-Pinto, M.M.; Ferreira, A.C.S.; Oliveira, C.; Caris-Veyrat, C.; Guedes de Pinho, P. Carotenoid, chlorophyll, and chlorophyllderived compounds in grapes and Port wines. J. Agric. Food Chem., 2005, 53, 10034-10041.

[31] Rodriguez-Amaya, D.B.; Kimura, M. Harvestplus handbook for carotenoid analysis. Harvestplus Technical Monograph: Washington DC, 2004.

[32] Haxo, F. Carotenoids of the mushroom Cantharellus cinnabarinus. Bot. Gaz., 1950, 112, 228-232.

[33] Barros, L.; Calhelha, R.C.; Vaz, J.A.; Ferreira, I.C.F.R.; Baptista, P.; Estevinho, L.M. Antimicrobial activity and bioactive compounds of Portuguese wild edible mushrooms methanolic extracts. Eur. Food Res. Technol., 2007, 225, 151-156.

[34] Mayne, S.T. Beta-carotene, carotenoids, and disease prevention in humans. FASEB J., 1996, 10, 690-701.

[35] Murtaugh, M.A.; Ma, K.N.; Benson, J.; Curtin, K.; Caan, B.; Slattery1, M.L. Antioxidants, carotenoids, and risk of rectal cancer. Am. J. Epidemiol., 2004, 159, 32-41.

[36] Bendich, A. Recent advances in clinical research involving carotenoids. Pure Appl. Chem., 1994, 66, 1017-1024.

[37] Paiva, S.A.R.; Russell, R.M. $\beta$-Carotene and other carotenoids as antioxidants. J. Am. Coll. Nutr., 1999, 18, 426-433.

[38] Woodall, A.A.; Britton, G.; Jackson, M.J. Carotenoids and protection of phospholipids in solution or in liposomes against oxidation by peroxyl radicals: Relationship between carotenoid structure and protective ability. Biochim. Biophys. Acta, 1997, $1336,575-586$.

(C) Ribeiro et al.; Licensee Bentham Open .

This is an open access article licensed under the terms of the Creative Commons Attribution Non-Commercial License (http://creativecommons.org/licenses/by$\mathrm{nc} / 3.0 /$ ) which permits unrestricted, non-commercial use, distribution and reproduction in any medium, provided the work is properly cited. 